\title{
Uterine Didelphys with Pregnancy Outcomes: A Case Report
}

\author{
Shahanaj Sharmin ${ }^{*}$ \\ Didarul Alam ${ }^{2}$ \\ Farzana Rahman ${ }^{3}$ \\ 'Department of Obstetrics and Gynaecology \\ Chattagram Maa-O-Shishu Hospital Medical College \\ Chittagong, Bangladesh. \\ ${ }^{2}$ Department of Paediatrics \\ Bangabandhu Memorial Hospital (USTC) \\ Chittagong, Bangladesh. \\ ${ }^{3}$ Department of Obstetrics and Gynaecology \\ Manikganj Health Complex \\ Manikgani, Bangladesh.
}

\section{*Correspondence to:}

\section{Dr. Shahanai Sharmin}

Associate Professor

Department of Obstetrics and Gynaecology

Chattagram Maa-O-Shishu Hospital Medical College

Chittagong, Bangladesh.

E-mail:sharmin35cmc@gmil.com

Mobile : +8801747051592

www.banglajol.info/index.php/CMOSHMCJ

\begin{abstract}
A didelphys uterus also known as a "double uterus" is one of the least common Mullerian duct anomalies. Uterine didelphys is a congenital malformation that result from complete failure of fusion of the ipsilateral Mullerian duct during embryonic development. Ideally, diagnosis should be made before pregnancy and labour to prevent adverse outcomes. Here reporting a case who was a 19 years old, $4^{\text {th }}$ gravida, Para: 0+3 (Spontaneous abortion) referred to Bangabandhu Memorial Hospital (BBMH) USTC, Chittagong at 35 weeks of pregnancy with severe abdominal pain by local physician from Raozan, Chittagong. On vaginal examination a longitudinal vaginal septum and two vagina were found. Uterine Didelphys was confirmed during emergency caesarean section and delivered $1.5 \mathrm{~kg}$ male baby with APGAR score $7 / 10$ and was referred to Neonatal Intensive Care Unit (NICU). Post operative recovery of the mother was uneventful. The baby was also discharged at the age of seven days with establishment of breast feeding. To avoid delayed diagnosis and associated adverse outcome clinicians should have high index of suspicion of uterine anomaly when assessing cases of dysfunctional labour.
\end{abstract}

Key words: Uterine Didelphys; Preterm delivery; Caesarean section; Neonatal Intensive Care Unit.

\section{INTRODUCTION}

The uterus is embryologically paramesonephric duct (Mullerian duct) origin. Mullerian duct anomalies are congenital defects of the female genital system that arise from abnormal embryological development of any degree of failure of fusion of Mullerian ducts or subsequent failure of resorption of the tissue results in a spectrum of clinical manifestations. Incidence of these abnormalities ranges from $0.5-5 \%$ in general population ${ }^{1-3}$. Uterine development normally occurs between 6 and 22 weeks of gestation.

The female genital tracts and urinary tracts are closely related, not only anatomically but also embryologically. About $10 \%$ of infants are born with some abnormality of the genitourinary system. Renal anomalies are the commonest associated features seen in $40 \%$ of cases ranging from complete agenesis to malabsorption (Usually a pelvic kidney $)^{4}$.

Uterine didelphys is a condition of lateral fusion defect where both mullerian duct fail to fuse causing presence of two hemi uteri and cervices. A longitudinal vaginal septum is also present that may range from thin and easily displaced to thick and inelastic. Initial suspicion of the condition followed by the diagnosis usually begins with routine speculum examination where visualization of anatomical abnormalities warrants further investigations. Pregnancy in such a uterus causes poor pregnancy outcome, like spontaneous abortion, preterm labor, abnormal presentation and increased incidence of caesarean delivery ${ }^{1,2,5}$. 
Most women with a didelphys uterus are asymptomatic, but some present with dyspareunia or dysmenorrhea in the presence of varying degree of vaginal septum. Rarely, genital neoplasms, hematocolpos/hematometrocolpos, and renal anomalies are reported in association with diadelphys uterus ${ }^{6}$.

The modalities of MDAs for the correct diagnosis frequently used include highly invasive methods such as hysteroscopy, hysterosalphingography and laparoscopy/laparotomy. The use of 3D ultrasound is more commonly used for diagnosis $6,7,8$. Magnetic Resonance Imaging (MRI) is also accurate and valuable in diagnosis MDAs as hysterosalpingogram, hysteroscopy and laparoscopy are even more. So it is noninvasive and can also diagnose associated urinary tract abnormalities at the same time ${ }^{9}$.

In this case report, we can discuss a rare case didelphys uterus in woman with history of recurrent miscarriage who successfully conceived, carried her pregnancy to 35 weeks and delivered by Lower Segment Caesarean Section (LSCS) due to preterm labor with thick longitudinal vaginal septum.

\section{CASE REPORT}

This patient is a 19 years old, $4^{\text {th }}$ gravida, para $0+3$ (Spontaneous recurrent abortion) hailing from,Hathazari, Chittagong. She had regular antenatal check up by local physician with duly immunized. Her LMP was $4^{\text {th }}$ Dec 2016 and accordingly her EDD was $11^{\text {th }}$ Sep 2017. Her menstrual cycle were regular and no
Figure 1 : Longitudinal Vaginal Septum.

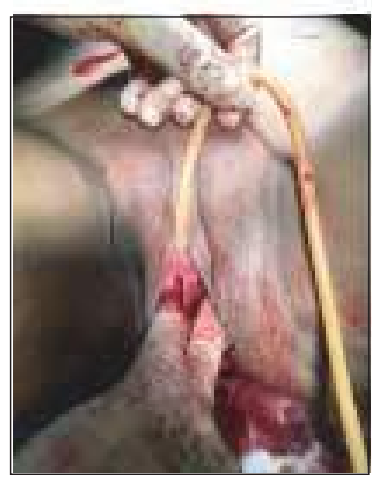

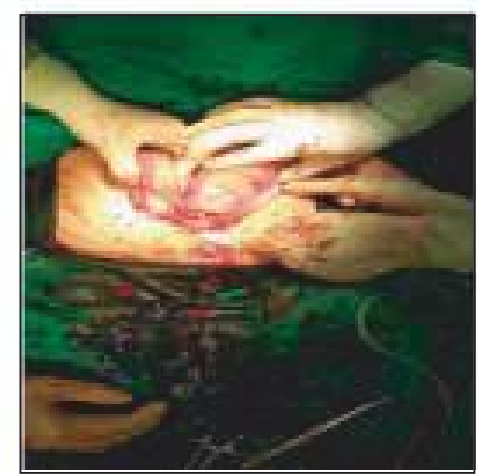

Figure 2 : Uterine Didelphys. history of dysmenorrhea. Pelvic sonogram at $8^{\text {th }}$ weeks of pregnancy showed diagnosis of bicornuate uterus. Her pregnancy was uneventful till 35 weeks of gestation. Two hours prior to admission, she noticed her lower abdominal pain which gradually increased its frequency and duration. After admission she was found average body built, normotensive, mild anemic. Perabdominal examination revealed uterus of 34 weeks gestation. Fetal heart rate $144 / \mathrm{min}$, regular and contraction present. On vaginal examination, patient had a non communication, longitudinal vaginal septum (Figure-1) but patient and her husband were not aware of the condition. She did not give any history of dysmenorrhea or dyspareunia.

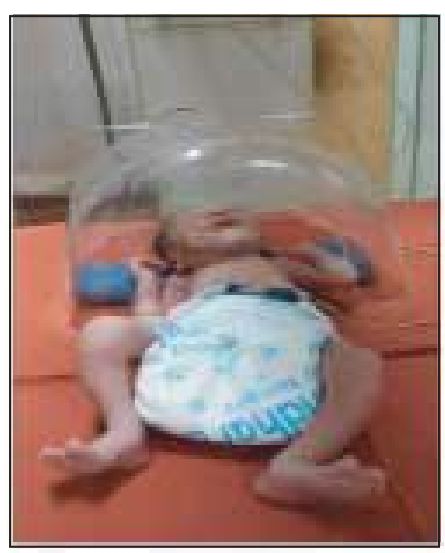

Figure 3 : Baby in NICU.

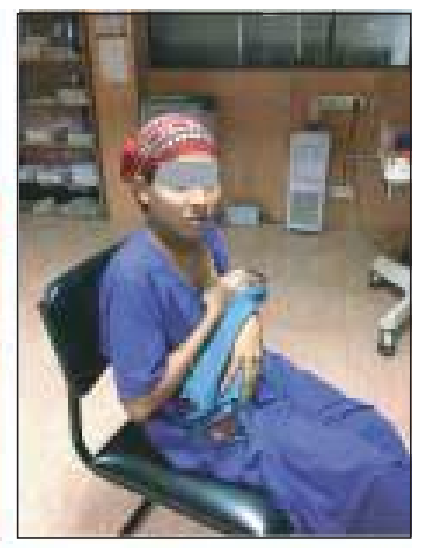

Figure 4 : Breast feeding during treatment.
For this reason emergency caesarean section was done on $12^{\text {th }}$ July 2017 at 34 weeks. Abdomen was opened up by pfannenstiel incision then lower segment caesarean section was done and delivered $1.5 \mathrm{~kg}$ male baby with APGAR score 7/10 and was referred to Neonatal Intensive Care Unit (Figure-3). Active management of $3^{\text {rd }}$ stage of labor was done and her $3^{\text {rd }}$ stage was uneventful. After delivery of baby, exteriorization of uterus done and showed at that time gravid uterus along with other hemi-uterus (Figure-2). Exploration of peritoneal cavity done to check normal position of kidney. Her post-operative period remained uneventful.The baby was discharged at the age of seven days with establishment of breast feeding (Figure-4).

\section{DISCUSSION}

Didelphys uterus is a very rare Mullerian duct anomaly in comparison to other anomalies described in the Buttram and Gibbons classification ${ }^{10}$. Unicornuate uterus was reported to have the poorest fetal survival, the didelphic uterus was believed to have $23 \%$ abortion rate and bad obstetrics outcome ${ }^{5}$.

Most woman with didelphys uterus are asymptomatic, but may present with dyspareunia or dysmenorrhea in the presence of a thick, sometimes obstructing vaginal septum. This obstructing vaginal septum can lead to hematocolpos or hematometrocolpos and patient present with chronic abdominal pain. Rarely genital neoplasms and endometriosis are reported in association with cases of didelphys uterus ${ }^{2,11}$

The association between having a Mullerian duct anomaly and fertility is debatable. Grimbizis et al found the incidence of MDAs in infertile patients $(3.4 \%)$ similar to that of general population and/or fertile women $(4.3 \%)$ which concluded that MDAs may not have negative impact on fertility ${ }^{12}$. In contrast Raga et al demonstrated the incidence of Mullerian duct anomalies to be significantly higher in infertile women than in fertile women, suggesting a link between infertility and the $\mathrm{MDA}^{13}$. A retrospective study on fertility and obstetric outcome done by Zhang et al in China demonstrated that women with didelphys uterus more frequently required infertility treatment than other anomalies to conceive ${ }^{14}$. 
Some measures may be undertaken to increase fertility, decrease chances of prematurity and improve the quality of life. Surgical correction of a didelphys uterus (Metroplasty) is not usually indicated and the literature on women with didelphys uterus who underwent Metroplasty is very limited. Observational studies women with septate or bicornuate uteri worth a history of repeated anomalies and infertility demonstrating improvement in reproduction and gestational outcome after metroplasty ${ }^{12}$. Longitudinal vaginal septum excision is considered if the women is symptomatic complaining of dyspareunia or pain from hematometrocolpos due to obstruction. Some septa can be easily displaced to the side to facilitate vaginal birth and others may be thick and inelastic, increasing the risk of vaginal dystocia and requiring excision. A didelphys uterus is not an indication for cesarean delivery and this vaginal delivery should be considered first $^{6,15,16}$. One case report identified this syndrome in a newborn who was diagnosed with renal agenesis in utero and born with a protruding vaginal mass and a hydrocolpos was found on imaging ${ }^{17}$.

\section{CONCLUSIONS}

Among the Mullerian duct anomaly the didelphys uterus is very rare. The reproductive and gestational outcomes in comparison to other common abnormalities are varied. Didelphys uterus is not an indication for caesarean delivery unless the vaginal septum is thick and inelastic resulting in an increased risk for vaginal dystocia. When a didelphys uterus is diagnosed, renal anomalies should also be investigated. At present, literature regarding didelphys uterus are limited. So, to determine the reproductive and gestational outcomes more studies are needed. As aresult the clinicians can adequately advise and care for their parents.

\section{DISCLOSURE}

All authors declared no competing interest.

\section{REFERENCES}

1. Grimbizis GF, Camus M, Tarlatzis BC, Bontis JN and Devroey. Clinical implications of uterine malformations and hysterescopic treatment results. Human Reproduction update. 2001;7(2):161-174.

2. Heinonen Pk. Uterine Didelphys: A report of 26 cases. EurJ.ObstetGynecolReprod Biology. 1984;17(5):345-350

3. Maiti SCG, Tugnait MP, Anand SCA, Garg SCS, Uterine Didelphys with pregnancy and cervical incompetence, MJAFI. 2006;62(2):200-208.

4. Kumar P, Malhotra N. Jeffcoate's Principles of Gynecology. Jaypee Brothers Medical Publishers Ltg. New Delhi. $7^{\text {th }}$ edition. 2008;196-199.

5. Rock JA, Breech LL Surgery for anomalies of Mullerian ducts, in John A Rock, HawardsW.Jones III, Editors. Telinde's Operative Gynecology, $9^{\text {th }}$ edition, Lippincott Williams \& Wilkins. 2003;732-736.

6. Rezai S, Bisram P, Aleantara IL, Upadhyay R, Lara C and Elmadjian M. Didelphys Uterus: A case report and reviews of the literature. Hindawi publishing corporation case reports in obstetrics and Gynecology 2018 [Cited 2017 Sep 5] Available from; http://dx.doi.org/10.1155/2015/865821.

7. Woelfer B, Salim R, Banerjees, Elson J, Regan L and Jurkovic D, Reproductive outcomes in women with congenital uterine anomalies defected by three-dimensional ultrasound screening. Obstetrics \& Gynecology. 2001;98(6):1099-1103.

8. Raga F, Bonilla-Musoles F, Blanes J and Osborne N.G. Congenital Mullerian anomalies: Diagnostic accuracy of three dimensional ultrasound. Fertility and sterility,1996; 65(3):523-528.

9. Takagi H, Matsunami K, Noda K, Fursui T and Imai A, "Magnetic resonance imaging in the evaluating of double uterus and associated urinary tract anomalies: A report of five cases. Journal of Obstetric and Gynecology. 2003;23(5):525-527.

10. Buttram V.C Jr, Gibbons W.E. "Mullerian anomalies: a proposed classification. (An analysis of 144 cases)” Fertility and sterility. 1979;32(1):40-46.

11. Martinez-Meltran M, Gimenez J and Acien P. "Uterus didelphys with septate cervix and unilateral endometrial carcinoma: A case report, "Journal of Genital system \& Disorders. 2012;1(1).

12. Grimbizis G.F, Camus M, Tarlatzis B.C, Bontis J.N and Devoey P. Clinical implications of uterine malformations and hysterescopic treatment results, Human Reproduction Update. 2001;7(2):161-174.

13. Raga F, Bauset C, Remohi J, Bonilla-MusolesF, Simoin C and Pellicer A. Reproductive impact of congenital anomalies, Human Reprocution, 1997;12(10):2277-2281.

14. Zhang Y, Zhao Y.Y and Qiao J. Obstetrics outcome of women with uterine anomalies in China, Chinese Medical Journal. 2010;123(4):418-422.

15. Suthar. S, Choudhary R. and Dadhich S, Rupture Uterus in pregnancy with Didelphys uterus: A rare case report. Journal of South Asian Federation of Obstetrics and Gynecology. 2011;3(3):149-150.

16. Altwerger G. Pritchard A.M. Black J.D and Sfakianaki A.K. Uterine Didelphys and vaginal birth after caesarean delivery. Journal of Obstetrics \& Gynecology.2015;125(1):157-159.

17. Wu T.H, Wu T.T, Ng Y.Y et al "Herlyn-Werner Wuderlich Syndrome consisting of uterine didelphys, obstructed hemivagina and ipsilateral renal agenesis in a newborn, Pediatrics \& Neonatology. 2012;53(1):68-71. 